\title{
Continuing professional development training needs of medical laboratory personnel in Botswana
}

Ishmael Kasvosve ${ }^{1 *}$, Jenny H Ledikwe ${ }^{2,3}$, Othilia Phumaphi ${ }^{2}$, Mulamuli Mpofu ${ }^{2}$, Robert Nyangah², Modisa S Motswaledi ${ }^{1}$, Robert Martin ${ }^{3}$ and Bazghina-werq Semo ${ }^{2,3}$

\begin{abstract}
Background: Laboratory professionals are expected to maintain their knowledge on the most recent advances in laboratory testing and continuing professional development (CPD) programs can address this expectation. In developing countries, accessing CPD programs is a major challenge for laboratory personnel, partly due to their limited availability. An assessment was conducted among clinical laboratory workforce in Botswana to identify and prioritize CPD training needs as well as preferred modes of CPD delivery.

Methods: A self-administered questionnaire was disseminated to medical laboratory scientists and technicians registered with the Botswana Health Professions Council. Questions were organized into domains of competency related to (i) quality management systems, (ii) technical competence, (iii) laboratory management, leadership, and coaching, and (iv) pathophysiology, data interpretation, and research. Participants were asked to rank their self-perceived training needs using a 3-point scale in order of importance (most, moderate, and least). Furthermore, participants were asked to select any three preferences for delivery formats for the CPD.

Results: Out of 350 questionnaires that were distributed, 275 were completed and returned giving an overall response rate of $79 \%$. The most frequently selected topics for training in rank order according to key themes were (mean, range) (i) quality management systems, most important (79\%, 74-84\%); (ii) pathophysiology, data interpretation, and research (68\%, 52-78\%); (iii) technical competence (65\%, 44-73\%); and (iv) laboratory management, leadership, and coaching (60\%, 37-77\%). The top three topics selected by the participants were (i) quality systems essentials for medical laboratory, (ii) implementing a quality management system, and (iii) techniques to identify and control sources of error in laboratory procedures. The top three preferred CPD delivery modes, in rank order, were training workshops, hands-on workshops, and internet-based learning. Journal clubs at the workplace was the least preferred method of delivery of CPD credits.
\end{abstract}

Conclusions: CPD programs to be developed should focus on topics that address quality management systems, case studies, competence assessment, and customer care. The findings from this survey can also inform medical laboratory pre-service education curriculum.

Keywords: Continuing professional development, Curriculum, Developing countries, Medical laboratory, Training needs

\footnotetext{
* Correspondence: ishmael.kasvosve@mopipi.ub.bw

'Department of Medical Laboratory Sciences, University of Botswana, Private Bag UB 00712, Gaborone, Botswana

Full list of author information is available at the end of the article
} 


\section{Background}

Health professional boards worldwide are increasingly requiring practitioners to demonstrate their engagement with continuing professional development (CPD) in order to maintain competence in light of the ever-changing scope of practice and technological advances in the medical sciences. The enforcement of this requirement varies from country to country and between professions. The objective of CPD is to maintain high standards of competence in terms of knowledge, skills, and behavior $[1,2]$. Literature exists indicating that CPD in the health professions is effective in improving healthcare, patient outcomes, and population health. For example, participation in CPD activities by physicians has been shown to improve the quality of care given to patients and the public [3]. Studies have also shown that physicians who engage in CPD are more likely to accept new and effective treatment modalities and discontinue use of existing lower-benefit practices resulting in improved patient outcomes [4].

Health professional boards in some developed countries have embraced CPD as an effective way of maintaining and improving competencies of health professionals and have made them mandatory $[5,6]$. For example, participation in CPD for medical laboratory scientists is a prerequisite for a salary adjustment and career advancement in developed countries [7-10]. Health professional boards in developing countries are making progress in establishing and enforcing CPD requirements for re-licensing [11]. In Uganda and South Africa, regulatory bodies require completion of CPD credits in order to re-register [12]. Despite the benefits of CPD engagement on patient outcomes, in some developing countries there are several challenges regarding access to CPD programs [13]. Hindrances to participation in CPD include limited internet facilities to access online CPD programs, infrequent national professional meetings, lack of funding to attend regional and international conferences, and few to nonexistent national CPD providers that specifically cater for medical laboratory professionals. In most cases, the only opportunities available for CPD are the non-structured inhouse trainings organized by employers.

In Botswana, as in many other developing countries, formal CPD programs to address lifelong learning needs of laboratory professionals are lacking. The Botswana Health Professions Council (BHPC), the licensing board for healthcare workers, now requires medical laboratory scientists and technicians to accumulate CPD credit points as part of their career-long learning and to retain professional registration [14]. Since the focus of CPD is to enhance roles and competencies so as to improve patient outcomes through improved practice, CPD activities should be planned and designed (i) to address the current needs of the laboratory professionals, (ii) for re-registration, and (iii) to foster innovation.

The development of CPD programs must be based on an empirical assessment of needs and planners should focus on addressing shortfalls between existing knowledge or skill and needed competencies [15-17]. Consequently, needs assessment studies should focus on the actual and predicted professional practice requirements, related enabling competence and capabilities, and corresponding learning and change requirements [18]. Studies have shown that the format of CPD is strongly linked to improvement of competence, with educational techniques that are centered on interaction and active participation (e.g., case discussion, role-play, hands-on practice sessions) being more effective than practice guidelines and formal instruction (e.g., didactic lectures, seminars) [19,20]. In the development of an effective CPD program, it is therefore important to understand both the specific needs of the target population, and to investigate appropriate educational formats for CPD delivery.

The primary objective of this needs assessment survey was to identify and prioritize current development needs of medical laboratory scientists and technicians in order to address performance requirements. Secondly, we wanted to identify the format preferences for CPD delivery for medical laboratory scientists and technicians in Botswana.

\section{Design and methods \\ Study design}

This was a descriptive cross-sectional assessment utilizing a self-administered questionnaire.

\section{Study population}

A questionnaire was distributed to 350 medical laboratory scientists and technicians registered with the BHPC. A laboratory technician is defined as a professional holding a diploma qualification in medical laboratory technology obtained after three years of post-high school study, and a laboratory scientist holds a bachelor's degree in medical laboratory sciences. The population surveyed included professionals working in clinical laboratories, medical laboratory supplies businesses, and training and research institutions. Since the target population was finite and could theoretically be accessed at economical costs, the study intended to recruit the entire target population. Informed consent was obtained from the study participants. The protocol was approved by Institutional Review Boards at the University of Botswana and University of Washington. A Research Permit was obtained from the Botswana Ministry of Health.

\section{Data collection}

The questionnaire was developed with input from various stakeholders which included representatives of employers, 
training institutions, and a professional society for laboratory professionals. Questions were organized into key domains of competency related to (i) quality management systems, (ii) technical competence, (iii) laboratory management, leadership, and coaching, and (iv) pathophysiology, data interpretation, and research. Participants were asked to rank their self-perceived training needs using a 3-point scale in order of importance (most, moderate, and least). Furthermore, participants were asked to select any three preferences for delivery formats for the CPD activities from a list of seven options, namely face-to-face presentations, live video conference, hands-on workshops, journal club at the workplace, webcast of distance lecture/internet-based teaching modules, training workshops, and directed learning in the workplace followed by a quiz.

According to the literature, potential learners themselves are considered the best source of information about their training needs, but this approach alone might not give the full picture of the clinical laboratories' training priorities [21]. Therefore, to address this limitation, the study also solicited views of participants in supervisory roles $(n=90)$. The supervisors completed additional questions addressing the training needs of the staff they supervised. The questionnaire was disseminated in-person or via e-mail, with a follow-up telephone call to confirm if the practitioner had received the questionnaire. Furthermore, at every site we selected one practitioner to collect the completed questionnaires and return them by post.

\section{Data analysis}

The data collected by the questionnaire was entered into a spreadsheet and data analysis was performed using SPSS version 19 software. We generated descriptive statistics to characterize the demographics of the respondents. Frequencies were used to report individuals who identified each CPD key theme and topic. We also generated frequencies to report preferences of CPD method of delivery. A $\chi^{2}$ test was used to compare training needs between medical laboratory scientists and laboratory technicians; and according to number of years of postqualification experience ( $<10$ years vs. $\geq 10$ years).

Topics to be included in CPD programs to be developed were prioritized as follows: topics given a most importance rating by $\geq 80 \%$ of the respondents (priority 1 ); 70 to $79 \%$ (priority 2); 60 to $69 \%$ (priority 3 ), and $\leq 59 \%$ (priority 4).

\section{Results}

\section{Characteristics of the study population}

Three hundred and fifty questionnaires were distributed to laboratory scientists and technicians and 275 (79\%) responded to the survey, of which $56 \%$ were employed as medical laboratory technicians, $32 \%$ as medical laboratory scientists, $4 \%$ as laboratory managers, and $8 \%$ were employed in teaching or research institutions (Table 1). The participants had varying years of service, ranging from less than one year to over 10 years of experience. The majority (85\%) were working in a public sector laboratory and the rest were employed in the private sector or a training/research institution. Ninety participants performed supervisory roles at their workplace; 34 (38\%) supervised 1 to 4 staff members; while 31 (34\%), 10 (11\%), and $12(13 \%)$ supervised 5 to 9,10 to 14 , and more than 15 staff members, respectively.

\section{CPD educational preferences of the laboratory personnel}

The most frequently selected topics for training in rank order according to key themes were (i) quality management systems, most important (mean, range 79\%, 74\% to $84 \%$ ); (ii) pathophysiology, data interpretation, and research $(68 \%, 52 \%$ to $78 \%$ ); (iii) technical competence (65\%, $44 \%$ to $73 \%$ ); and (iv) laboratory management, leadership, and coaching (60\%, 37\% to $77 \%$ ) (Table 2 ). Most medical laboratory professionals in Botswana felt they needed more training on topics in quality management systems. Laboratory management, leadership, and coaching was the least rated skills domain.

Table 1 Demographic characteristics of participants $(n=275)$

\begin{tabular}{|c|c|c|}
\hline & Frequency & Percentage \\
\hline \multicolumn{3}{|l|}{ Cadre type } \\
\hline Medical laboratory technicians & 153 & 55.6 \\
\hline Medical laboratory scientists & 89 & 32.4 \\
\hline Laboratory managers & 12 & 4.4 \\
\hline Others* & 21 & 7.6 \\
\hline \multicolumn{3}{|l|}{ Years of service } \\
\hline$<1$ year & 22 & 8 \\
\hline $1-5$ years & 73 & 26.4 \\
\hline $6-10$ years & 72 & 26.4 \\
\hline$>10$ years & 105 & 38.0 \\
\hline Not specified & 3 & 1.1 \\
\hline \multicolumn{3}{|l|}{ Current place of work } \\
\hline Ministry of Health laboratory & 234 & 85.1 \\
\hline Private laboratory & 30 & 10.9 \\
\hline Military hospital laboratory & 3 & 1.1 \\
\hline Educational or research institution & 5 & 2.2 \\
\hline Not specified & 3 & 0.7 \\
\hline \multicolumn{3}{|l|}{ Supervisory responsibilities } \\
\hline Number reporting supervisory roles & 90 & 33 \\
\hline Number not reporting supervisory roles & 185 & 67 \\
\hline
\end{tabular}

*These participants were either working for a non-governmental organization or a training institution. 
Table 3 prioritizes the training topics according to the ranking by the participants; $80 \%$ or more of the participants felt they needed training on (i) quality systems essentials in the medical laboratory, (ii) implementing a quality management system, and (iii) techniques to identify sources of error in laboratory procedures.

Overall, the ranking of training needs was comparable between medical laboratory scientists and technicians. There was no difference between the two cadres for the skills domains technical competence and laboratory management, leadership, and coaching. For some topics on pathophysiology, data interpretation, and research, more technicians felt they needed the training compared to medical laboratory scientists. However, the majority $(\geq 56 \%)$ in each group selected the same topics for CPD training. Comparison of training needs according to post-qualification experience revealed no marked differences for most topics, but more recently qualified laboratory professionals ( $\leq 10$ years' experience) felt they needed training on case studies and competence assessment than those with $>10$ years' experience $(P<0.05)$.

\section{Training needs identified by supervisors}

Ninety participants holding supervisory positions identified topics on technical competency (24\%), and a similar proportion (23\%) identified laboratory management, leadership, and coaching as key themes of greatest training need for their staff; $14 \%$ of the supervisors felt there was a need to train staff on topics on quality management systems.

\section{Preferred format for CPD}

The top three preferred CPD delivery modes, in rank order, were training workshops (218/275 participants), hands-on workshops (163/275 participants), and internetbased learning (156/275 participants) (Figure 1). A journal club at the workplace was the least preferred method of delivery and was selected by only 32 participants.

\section{Discussion}

CPD is essential in supporting sustained competence of the healthcare workforce. This is the first study to report on CPD needs and educational preferences for medical laboratory personnel in Botswana. Generally, the ranking of training needs by the survey respondents did not vary by qualification or years of experience, with the topics selected being comparable between medical laboratory scientists and laboratory technicians. However, the less experienced personnel felt they needed training on case studies compared to the more experienced staff.

The majority of respondents identified topics on quality management systems, case studies, competence assessment, and customer care as the most important for training. Most of the public sector laboratories in Botswana are in the process of implementing quality management systems [Matema D, Chief Scientific Officer, Ministry of Health, Oral communication, 2014]. Laboratory personnel may feel the need to learn more about quality management systems in order to successfully implement the process in their laboratories; this may be the reason behind the greatest need for training in quality

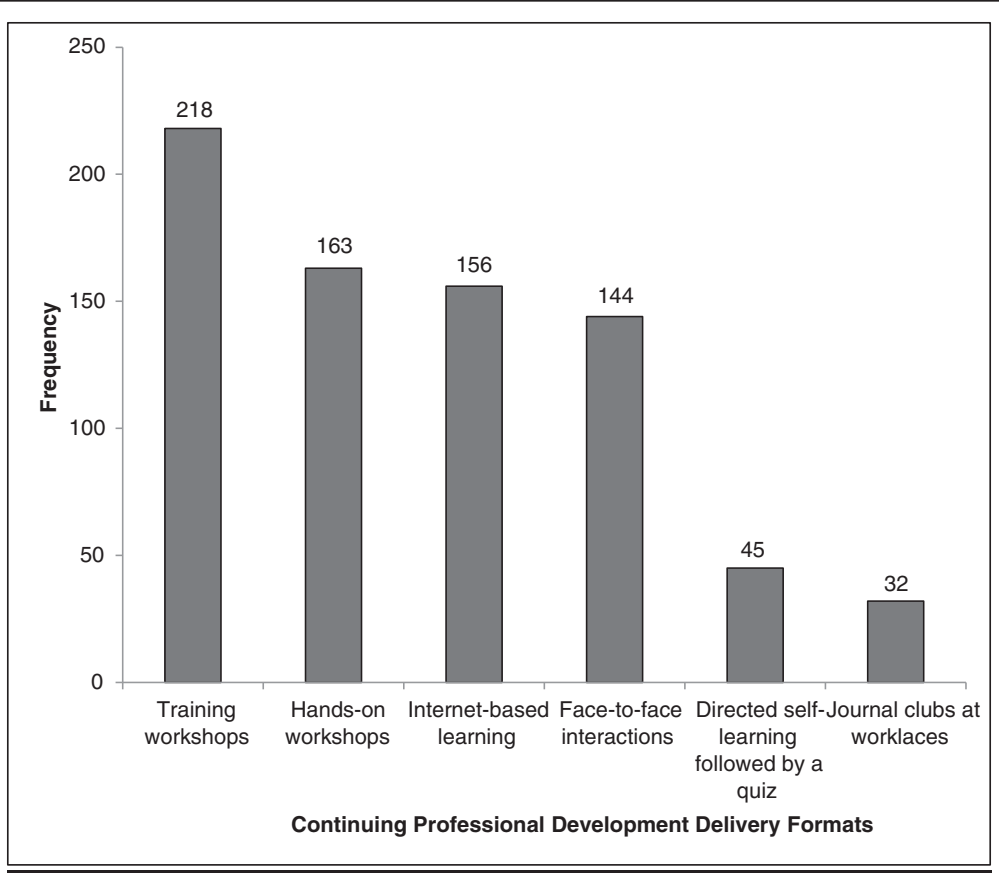

Figure 1 Format preferences for delivery of continuing professional development activities, $n=275$. 
Table 2 Ranking of training needs according to pre-determined themes/domains, $\mathbf{n}=\mathbf{2 7 5}$

\begin{tabular}{|c|c|c|c|c|}
\hline \multirow[t]{2}{*}{ Training needs } & \multicolumn{4}{|l|}{ Ranking } \\
\hline & $\begin{array}{l}\text { Most important } \\
\text { n (\%) }\end{array}$ & $\begin{array}{l}\text { Moderate importance } \\
\mathrm{n}(\%)\end{array}$ & $\begin{array}{l}\text { Low importance } \\
\text { n (\%) }\end{array}$ & $\begin{array}{l}\text { No response } \\
\mathrm{n}(\%)\end{array}$ \\
\hline \multicolumn{5}{|l|}{ Quality management systems } \\
\hline Quality system essentials for medical laboratory & $230(84)$ & $20(7)$ & $8(3)$ & $17(6)$ \\
\hline Implementing a quality management system & $230(84)$ & $23(8)$ & $4(2)$ & $18(7)$ \\
\hline $\begin{array}{l}\text { Techniques to identify and control sources of errors in laboratory } \\
\text { procedures }\end{array}$ & $220(80)$ & $29(11)$ & $5(2)$ & $21(8)$ \\
\hline Management of non-conformances in laboratory services & $213(78)$ & $37(14)$ & $6(2)$ & $19(7)$ \\
\hline Use of external quality assessment to improve testing procedures & $202(74)$ & $39(14)$ & $9(3)$ & $25(9)$ \\
\hline Internal quality control and Westgard rules & $211(77)$ & $33(12)$ & $8(3)$ & $23(8)$ \\
\hline Laboratory accreditation: principles and processes & $211(77)$ & $35(13)$ & $6(2)$ & $23(8)$ \\
\hline Clinical laboratory safety & $209(76)$ & $35(13)$ & $10(4)$ & $21(8)$ \\
\hline \multicolumn{5}{|l|}{ Technical competence } \\
\hline Evidence-based laboratory medicine & $188(68)$ & $52(19)$ & $12(4)$ & $23(8)$ \\
\hline Evaluation and selection of analytical methods and equipment & $193(70)$ & $54(20)$ & $9(3)$ & $19(7)$ \\
\hline Definition, establishment, and use of reference ranges & $192(70)$ & $49(18)$ & $12(4)$ & $22(8)$ \\
\hline Health informatics & $149(54)$ & $89(32)$ & $10(4)$ & $27(10)$ \\
\hline Point of care testing & $122(44)$ & $99(36)$ & $32(12)$ & $22(8)$ \\
\hline Statistics in laboratory medicine & $180(66)$ & $68(25)$ & $11(4)$ & $16(6)$ \\
\hline Specimen management & $201(73)$ & $36(13)$ & $15(6)$ & $23(8)$ \\
\hline Molecular diagnostic methods and genetics & $190(69)$ & $59(22)$ & $14(5)$ & $12(4)$ \\
\hline Laboratory and disease surveillance & $186(68)$ & $62(23)$ & $5(2)$ & $22(8)$ \\
\hline Equipment maintenance & $176(64)$ & $50(18)$ & $16(6)$ & $33(12)$ \\
\hline \multicolumn{5}{|l|}{ Laboratory management, leadership, and coaching } \\
\hline Customer care & $211(77)$ & $34(12)$ & $11(4)$ & $19(7)$ \\
\hline Competence assessment & $197(72)$ & $49(18)$ & $10(4)$ & $19(7)$ \\
\hline Ethics and professionalism & $159(58)$ & $78(28)$ & $16(6)$ & $22(8)$ \\
\hline Supervision and delegation & $134(49)$ & $95(35)$ & $19(7)$ & $27(10)$ \\
\hline Preceptorship and mentorship & $196(71)$ & $57(21)$ & $12(4)$ & $10(4)$ \\
\hline Data management, report writing, and presentation skills & $126(46)$ & $100(37)$ & $23(8)$ & $26(10)$ \\
\hline Basic cost accounting for clinical laboratory services & $183(67)$ & $58(21)$ & $11(4)$ & $23(8)$ \\
\hline Management of resources and supplies & $185(67)$ & $56(20)$ & $10(4)$ & $24(9)$ \\
\hline Monitoring and evaluation & $166(60)$ & $72(26)$ & $16(6)$ & $21(8)$ \\
\hline Team building & $188(68)$ & $54(20)$ & $12(4)$ & $21(8)$ \\
\hline Strategic planning & $184(67)$ & $61(22)$ & $10(4)$ & $20(7)$ \\
\hline Rational selection of tests & $162(59)$ & $75(28)$ & $13(5)$ & $25(9)$ \\
\hline Medical tariffs (billing and coding) & $102(37)$ & $95(35)$ & $49(18)$ & $29(11)$ \\
\hline Costing of laboratory tests and procedures & $117(43)$ & $93(34)$ & $38(14)$ & $27(10)$ \\
\hline \multicolumn{5}{|l|}{ Pathophysiology, data interpretation, and research } \\
\hline Case studies in clinical microbiology & $214(78)$ & $34(12)$ & $8(3)$ & $19(7)$ \\
\hline Case studies in clinical chemistry & $200(73)$ & $40(15)$ & $9(3)$ & $26(10)$ \\
\hline Case studies in hematology & $208(76)$ & $38(14)$ & $8(3)$ & $21(8)$ \\
\hline Case studies in medical parasitology & $202(74)$ & $36(13)$ & $12(4)$ & $25(9)$ \\
\hline Case studies in blood transfusion science & $207(75)$ & $36(13)$ & $11(4)$ & $21(8)$ \\
\hline Case studies in cytology and histology & $183(67)$ & $47(17)$ & $19(7)$ & $26(10)$ \\
\hline
\end{tabular}


Table 2 Ranking of training needs according to pre-determined themes/domains, $\mathbf{n}=\mathbf{2 7 5}$ (Continued)

\begin{tabular}{lllll}
\hline Research proposal development and operational research & $194(71)$ & $43(16)$ & $12(4)$ & $26(10)$ \\
Grant proposal writing & $149(54)$ & $76(28)$ & $17(6)$ & $33(12)$ \\
Manuscript preparation & $142(52)$ & $76(28)$ & $47(7)$ & $35(14)$ \\
Basic computer skills (Microsoft suite) & $160(58)$ & $47(17)$ & $33(12)$ \\
\hline
\end{tabular}

management systems. It is also plausible that training addressing quality management systems in clinical laboratory services has not been fully integrated into pre-service education curricula [22]. A review of the diploma training program curriculum in Botswana conducted in 2007 recommended strengthening of training of quality management systems in pre-service programs [Motswaledi MS, Deputy Director of Clinical Services, Oral communication, 2008]. The identified need for training in laboratory quality management systems is in keeping with reported competence gaps in the laboratory workforce in resource-limited countries [23].

CPD programs on case studies should seek to address disease profiles in the country. Although research proposal development and operational research had a high priority, the related topics "grant proposal writing and manuscript preparation" received a low priority by the respondents.

Participants in supervisory roles were asked to identify learning needs of the staff they supervise. Surprisingly, the topics recommended by supervisors were not congruent with observations from their supervisees. The supervisors believed that CPD programs should focus on technical competence, laboratory management, leadership, and coaching. A possible reason for this variation is that self-assessments are more likely to be influenced by what the professionals think they will gain from a professional growth and future advancement perspective $[24,25]$, while supervisor assessments are likely to be

Table 3 Prioritization of topics for training according to ranking by participants

\begin{tabular}{|c|c|c|c|}
\hline $\begin{array}{c}\text { Priority } 1 \\
\geq 80 \%\end{array}$ & $\begin{array}{l}\text { Priority } 2 \\
70 \%-79 \%\end{array}$ & $\begin{array}{l}\text { Priority } 3 \\
60 \%-69 \%\end{array}$ & $\begin{array}{c}\text { Priority } 4 \\
(\leq 59 \%\end{array}$ \\
\hline $\begin{array}{l}\text { Quality system essentials for medical } \\
\text { laboratory }\end{array}$ & $\begin{array}{l}\text { Management of non-conformances } \\
\text { in laboratory services }\end{array}$ & $\begin{array}{l}\text { Evidence based laboratory } \\
\text { medicine }\end{array}$ & Health informatics \\
\hline $\begin{array}{l}\text { Implementing a quality management } \\
\text { system }\end{array}$ & $\begin{array}{l}\text { Use of external quality assessment to } \\
\text { improve testing procedures }\end{array}$ & $\begin{array}{l}\text { Statistics in laboratory } \\
\text { medicine }\end{array}$ & Point of care testing \\
\hline \multirow[t]{14}{*}{$\begin{array}{l}\text { Techniques to identify and control sources } \\
\text { of errors in laboratory procedures }\end{array}$} & $\begin{array}{l}\text { Internal quality control and Westgard } \\
\text { Rules }\end{array}$ & $\begin{array}{l}\text { Molecular diagnostic } \\
\text { methods and genetics }\end{array}$ & Ethics and professionalism \\
\hline & $\begin{array}{l}\text { Laboratory accreditation: principles } \\
\text { and processes }\end{array}$ & $\begin{array}{l}\text { Laboratory and disease } \\
\text { surveillance }\end{array}$ & Supervision and delegation \\
\hline & $\begin{array}{l}\text { Evaluation and selection of analytical } \\
\text { methods and equipment }\end{array}$ & Equipment maintenance & $\begin{array}{l}\text { Data management, report } \\
\text { writing and presentation skills }\end{array}$ \\
\hline & $\begin{array}{l}\text { Definition, establishment and use of } \\
\text { reference ranges }\end{array}$ & $\begin{array}{l}\text { Basic cost accounting for } \\
\text { clinical laboratory services }\end{array}$ & Rational selection of tests \\
\hline & Specimen management & $\begin{array}{l}\text { Management of resources } \\
\text { and supplies }\end{array}$ & $\begin{array}{l}\text { Medical tariffs (Billing and } \\
\text { coding) }\end{array}$ \\
\hline & Customer care & Monitoring and evaluation & $\begin{array}{l}\text { Costing of laboratory tests and } \\
\text { procedures }\end{array}$ \\
\hline & Competence assessment & Team building & Grant proposal writing \\
\hline & Preceptorship and mentorship & Strategic planning & Manuscript preparation \\
\hline & Case studies in clinical microbiology & $\begin{array}{l}\text { Case studies in cytology and } \\
\text { histology }\end{array}$ & $\begin{array}{l}\text { Basic computer skills (Microsoft } \\
\text { suite) }\end{array}$ \\
\hline & Case studies in clinical chemistry & & \\
\hline & Case studies in hematology & & \\
\hline & Case studies in medical parasitology & & \\
\hline & $\begin{array}{l}\text { Case studies in blood transfusion } \\
\text { science }\end{array}$ & & \\
\hline & $\begin{array}{l}\text { Research proposal development and } \\
\text { operational research }\end{array}$ & & \\
\hline
\end{tabular}


more focused on technical competencies required to improve laboratory testing.

The three most selected platforms of CPD delivery in rank order were training workshops, hands-on workshops, and internet-based learning. Training workshops and hands-on workshops are invariably more expensive than internet-based learning. These approaches may involve travelling and time spent away from work, whereas internet-based learning can be comparatively inexpensive. However, studies have shown that approaches involving interaction with learners are more effective educational techniques [26].

The selection of the CPD delivery platforms may be due to social desirability. Familiarity with the method could also have influenced the choice of methods. Training workshops with laboratory personnel travelling to a central site is a common approach of disseminating knowledge and skills in the country and this might also have influenced the choices selected by the respondents. Further, lack of reliable internet services and inadequate technology awareness could be reasons why most participants did not select internet-based platforms for CPD delivery. However, we did not ask the respondents to indicate comfort levels and access to internet services.

The other limitation to the study is that a single quantitative method was employed to identify CPD training needs of laboratory personnel. Population-based surveys are subject to low response rates and selection bias, thereby reducing the generalizability of the findings [27]. However, a mixed-methods approach (for instance, key informant interviews, and focus groups) to identify CPD training may address these shortcomings. The use of a variety of methods to confirm the same information by different methods or sources can increase the validity of the findings. In this study, $79 \%$ of the target population participated in the survey. Another potential limitation of the study was response bias. Since development and implementation of CPD programs in Botswana may be perceived by participants as being beneficial to their professional growth and addressing requirements for re-registration with the regulatory body, this may have motivated the target population to participate in the study.

The information on suggested topics and the form of delivery collected in this survey may be helpful in planning future CPD programs for medical laboratory workers in Botswana and the region. The findings from this survey can also inform medical laboratory pre-service education curriculum as well as focus the specific contribution that development partners may wish to render.

\section{Conclusions}

CPD programs should focus on topics that address quality management systems, competence assessment, customer care, and case studies on disease profiles common in Botswana. The three most preferred CPD delivery platforms in rank order were training workshops, hands-on workshops, and internet-based learning. However, when implementing CPD programs, providers need to determine the most effective and sustainable method for delivery of CPD content. While the findings from this survey provide a baseline data for medical laboratory science CPD program development, CPD providers should also consider future trends in laboratory medicine and advances in technology. Medical laboratory science pre-service education programs should also strengthen components of quality management systems in their curricula. Overall, it is noted that CPD needs will vary over time, depending on the prevailing challenges of the practice. This underscores the need for continuous evaluation of practice needs to remain relevant.

\section{Abbreviations}

BHPC: Botswana Health Professions Council; CPD: Continuing professional development.

\section{Competing interests}

The authors declare that they have no competing interests.

\section{Authors' contributions}

IK and RN conceived the study and design; IK, JL, OP, MM, and BS participated in the implementation of the study and data analysis. IK wrote the first draft and $J \mathrm{~L}$ and BS provided general oversight in implementing the study. All the authors participated in the write up, review, and approval of the manuscript.

\section{Acknowledgements}

The authors would like to thank staff from Botswana Ministry of Health, Botswana Health Professions Council, Centers for Disease Control Botswana, private medical laboratories, and the Botswana Institute of Clinical Laboratory Professionals for serving as members of the Reference Group.

\section{Funding Sources}

This work was supported by the US President's Emergency Plan for AIDS Relief (PEPFAR), through funding to the University of Washington and I-TECH from the US Department of Health and Human Services, Health Resources and Services Administration (HRSA) Global HIV/AIDS Bureau, Cooperative Agreement \# U91HA06801

\section{Author details}

${ }^{1}$ Department of Medical Laboratory Sciences, University of Botswana, Private Bag UB 00712, Gaborone, Botswana. Botswana International Training and Education Center for Health (I-TECH), P.O. Box AC46 ACH, Riverwalk, Gaborone, Botswana. ${ }^{3}$ Department of Global Health, University of Washington, 901 Boren Avenue Suite 1100 Seattle, WA 98104-3508, USA.

Received: 29 May 2014 Accepted: 11 August 2014 Published: 18 August 2014

\section{References}

1. College of Occupational Therapists: Professional Standards for Occupational Therapy Practice. London: COT; 2007.

2. World Federation for Medical Education (WFME): Continuing Professional Development of Medical Doctors: WFME Global Standards for Quality Improvement [http://www.wfme.org/standards/cpd/doc_download/16-continuingprofessional-development-cpd-of-medical-doctors-english]

3. Goulet F, Hudon E, Gagnon R, Gauvin E, Lemire F, Arsenault I: Effects of continuing professional development on clinical performance. Can Fam Physician 2013, 59:518-525. 
4. Davis D: Does CME work? An analysis of the effect of educational activities on physician performance or health care outcomes. Int J Psychiatry Med 1998, 28:21-39.

5. Department of Health: Working Together - Learning Together. London: HMSO; 2001

6. Mansouri M, Lockyer J: A meta-analysis of continuing medical education effectiveness. J Contin Educ Health Prof 2007, 27:6-15.

7. Lennon PA, Deleon E, Reynolds A, Pulido L, Lewing C, Mehta P, Biscanin S, Hai S, Bowman C, Galbincea J, Jakacky J, Hu P: A model for rewarding professional growth in the diagnostic molecular oncology laboratory. J Assoc Genet Technol 2011, 37:80-83.

8. Ali FA, Pulido LA, Garza MN, Amerson MH, Greenhill B, Brown KN, Lim SK, Manyan VR, Nguyen HN, Prudhomme CC, Regan LE, Sims WR, Umeh AU, Williams R, Tillman PK, Hu PC: A professional development model for medical laboratory scientists working in the Core Laboratory. Clin Lab Sci 2012, 25:67-73.

9. Garza MN, Pulido LA, Amerson M, Ali FA, Greenhill BA, Griffin G, Alvarez E, Whatley M, Hu PC: A professional development for medical laboratory scientists working in the immunohematology laboratory. Clin Lab Sci 2012, 25:2-6.

10. Mimura K, Mizuguti K: Certifying examination which college of laboratory medicine of Japan is sponsoring. Rinsho Byori 2012, 60:565-569.

11. Giri K, Frankel N, Tulenko K, Puckett A, Bailey R, Ross H: IntraHealth International: Keeping up to Date: Continuing Professional Development for Health Workers in Developing Countries. CapacityPlus: IntraHealth International; 2012 [www.intrahealth.org/page/keeping-up-to-datecontinuing-professional-development-for-health-workers-in-developingcountries]

12. Ndege S: Continuing professional development: a southern perspective. In International Hospital Federation Reference Book 2005/2006. Nairobi, Kenya: Pathfinder International; 2006 [http://www.ihf-fih.org/en/content/download/ 213/1361/file/42-ndege_jh.pdf]

13. Muula AS, Misiri H, Chimalizeni $Y$, Mpando D, Phiri C, Nyaka A: Access to continued professional education among health workers in Blantyre, Malawi. Afr Health Sci 2004, 4:182-184.

14. Council BHP: Guidelines for Continuing Professional Development (CPD). Ministry of Health: Gaborone; 2013.

15. Ulschak F: Creating the Future of Health Care Education. Chicago: American Hospital Publishing Co.; 1988.

16. Pearce SD: Needs assessment: constructing tacit knowledge from practice. Int J Lifelong Educ 1995, 14:405-419.

17. Gould D, Berridge EJ, Kelly D: The National Health Service Knowledge and Skills Framework and its implications for continuing professional development in nursing. Nurse Educ Today 2007, 27:26-34.

18. Aherne M, Lamble W, Davis P: Continuing medical education, needs assessment and program development: theoretical constructs. J Contin Educ Health Prof 2001, 21:6-14.

19. Davis DA, O'Brien MA, Freemantle R, Wolf FM, Mazmanian P, Taylor-Vaisey A: Impact of formal continuing medical education: do conferences, workshops, rounds and other traditional continuing education activities change physician behavior or health care outcomes? JAMA 1999, 282:867-874.

20. Bloom BS: Effects of continuing medical education on improving physician clinical care and patient health: a review of systematic reviews. Int J Technol Assess Health Care 2005, 21:380-385.

21. Gibson MJE: Using the Delphi technique to identify the content and context of nurses' continuing professional development needs. J Clin Nurs 1998, 7:451-459.

22. Fonjungo PN, Kebede $Y$, Arneson W, Tefera D, Yimer K, Kinde S, Alem M, Cheneke W, Mitiku H, Tadesse E, Tsegaye A, Kenyon T: Preservice laboratory education strengthening enhances sustainable laboratory workforce in Ethiopia. Hum Resour Health 2013, 11:56.

23. Nkengasong JN, Mesele T, Orloff S, Kebede $Y$, Fonjungo PN, Timperi R, Birx $D$ : Critical role of developing national strategic plans as a guide to strengthen laboratory health systems in resource-poor settings. Am J Clin Pathol 2009, 131:852-857.

24. Colthart I, Bagnall G, Evans A, Allbutt H, Haig A, Illing J, McKinstry B: The effectiveness of self-assessment on the identification of learner needs, learner activity, and impact on clinical practice: BEME Guide no. 10. Med Teach 2008, 30:124-145.
25. Eva KW, Regehr G: Self-assessment in the health profession: a reformulation and research agenda. Acad Med 2005, 80:S46-S54.

26. Bluestone J, Johnson P, Fullerton J, Carr C, Alderman J, Tempo J: Bon Effective in-service training design and delivery: evidence from an integrative literature review. Hum Resour Health 2013, 11:51.

27. Lockyer J: Getting started with needs assessment: part 1-the questionnaire. J Contin Educ Health Prof 1998, 18:58-61.

doi:10.1186/1478-4491-12-46

Cite this article as: Kasvosve et al: Continuing professional development training needs of medical laboratory personnel in Botswana. Human

Resources for Health 2014 12:46.

\section{Submit your next manuscript to BioMed Central and take full advantage of:}

- Convenient online submission

- Thorough peer review

- No space constraints or color figure charges

- Immediate publication on acceptance

- Inclusion in PubMed, CAS, Scopus and Google Scholar

- Research which is freely available for redistribution

Submit your manuscript at www.biomedcentral.com/submit
C) Biomed Central 